\title{
Building Arches: Typological Potential of an Architectural Form
}

\author{
Anna Gelfond ${ }^{1, *}$ \\ ${ }^{1}$ Architecture and Design Department, Nizhny Novgorod State University of Architecture and Civil Engineering, Nizhny \\ Novgorod, Russia \\ *Corresponding author. E-mail: gelfond@bk.ru
}

\begin{abstract}
The article considers typological potential of the architectural form of buildings-arches. The main message of the article is approbation by this example of theoretical provisions of special typology. The analysis is performed from several points of view: town-planning - a building-arch is investigated as an element of a large public space; compositional - subtraction technique - an aperture is cut off in an integral volume to the entire or incomplete height; addition technique - independent tower volumes are connected between each other by a third volume, i.e. a bridge-passage; typological buildings of office-business centres and supermarkets, station complexes, technoparks, dwelling houses and multifunctional constructions are studied; functional-layout - functional content of the architectural form constituents, organization of external and internal communications are analyzed; psychological and sign-symbolic - the form of an arch as a unity in confrontation, a symbol of success and an invitation for co-operation; buildings-arches are classified depending on their typological potential as follows: gate, window, frame-portal; passage; filled arches, transitional type.
\end{abstract}

\section{Keywords: building-arch, typological potential, public building, public space, architectural form}

\section{INTRODUCTION}

An arch from the design viewpoint is an overhead span between two supports, from the compositionalartistic one - it is a completed and effective architectural form, from the sign-symbolic point of view - it is an established symbol of success, reliability, strength, on one hand, and a window into a new world, on the other hand. Probably, the same ideology is inherent in buildings-arches ("Fig. 1"), which are identified in the practice of foreign and domestic architectural design as objects of various functional purposes. Let us consider buildings-arches or buildings imitating an arch from the point of view of their typological potential.

Introducing the notion "typological (or special) potential" of an architectural object, we express the idea that it is formed on the basis of functional, constructive and compositional-artistic potential. Anyhow, it is not the pure combination thereof, but something of a new integrated quality.

I.G. Lezhava pointed out that "an architectural form integrated the spatial, figurative and functional origins" and that "any form possessed a certain functional potential widening the spectrum of its purpose". He wrote: "The functional potential is a generalizing term incorporating an extensive hierarchy of polysemantic concepts... Adaptation capabilities, perhaps, is one of the bases on which interaction of the architectural form and function develops" [1]. It is true that function is the most flexible typological constituent from the viewpoint of ensuring the viability of an object. It is a function that at some point can dictate any form, as well as obey any form [2].

A.G. Rappaport wrote that "the functionalist concept should be referred to one of the most common symbolic concepts of architectural form in the professional mind... The function name is a kind of symbol, but this symbol is usually expressed not only by the name, but also by various morphological models, for example, behavior diagrams or traffic flow diagrams in a structure" [3].

A.V. Ikonnikov defined the function and the form of an architectural object like this: “...The function is the whole complex of various tasks solved by the architecture, both material and informational"; "...the form of an architectural object expresses the way it is organized and the way it exists in the context of the environment and culture". And, he further widened the conception of the architectural form: "There are three tactics for turning technology into an object form. The first concept assumes that the nature of the production process is one of the sources of its design. The second concept of the technological form is based on the 
figurative expression of an ideal technology realized by some other means. The third one supposes excluding traces of the process from the figurative language of the architecture. It is based on the principle of universality of the form bearing semantic meanings regardless of the purpose of the object, its material and method of implementation" [4].

In this article we will speak about just one architectural form - buildings-arches from the point of view of exactly this third concept. Analyzing the potential of their architectural form for structures of various functional purposes, we will try to identify what type of objects this "rigid" form is suitable for.
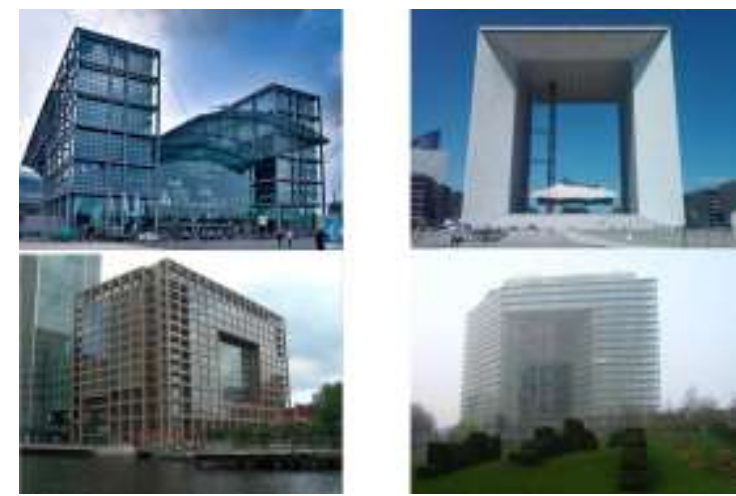

Fig. 1. Buildings-arches.

\section{GATE, WINDOW}

When viewing such an object, the first immediately recognizable layer of associations is the gate and window in the architectural space of the city. It is widely known that buildings-arches are used as symbolic gates or portals of the main entrance to public and business areas of cities - the "City gate" of the Media-port in Dusseldorf, the Great Arch of the Defense in Paris, the "Sky garden" in Osaka.

The building of the business centre "City gate" (arch. Petzinka, Overdiek and Partners, 1992-1998) in Dusseldorf is located at the entrance to a large public space - the Media-port. Such a location of the building had dictated the compositional role and the form of the object: two towers connected by three top floors. In plan, the building is a parallelogram with sides $66 \mathrm{~m} \mathrm{x}$ $50 \mathrm{~m}$. An energy-saving building with low energy consumption, an adaptive ventilated façade and a huge atrium $(\mathrm{h}=58 \mathrm{~m})$, the object presents a modern and important business centre. The building is surrounded by an open "labyrinth" of plant sculptural forms - the landscape park Bilk designed by landscape architect Georg Penker who called it "artificial jungles" — a space for contemplation and attitude for business [5].

The Great Arch of the Defense (arch. Johan Otto von Spreckelsen, 1982-1989), located on a historic axis of Paris, is the centre of the composition of a large region, a multi-time ensemble and at the same time their symbol. It is achieved by the majestic installation of the volume, the ideally found physical parameters, and the colour solution, which allowed to combine in this object the polar features that have long been inherent in business centres: fundamental and easy, solid and democratic. The rational decision of the main volume is in contrast with a "floating cloud" in the arch opening.

The Umeda Sky Building (arch. Hara Hiroshi) is located in the Kita-ku ward of Osaka, 1988-1993. This is a high-density area of the city, the main type of buildings in which is prismatic towers. The building was constructed within the frameworks of the City of Air project, 1988, and initially had been designed to have four towers, but during the work their number was reduced to two. The 40-story arch is spanned on the 39th floor by the observation deck "Garden in the Sky", which looks "like a soaring Paradise with a complex artificial landscape with rural picturesque features and intimate scale" [6]. The towers are completed with an imposing stepped silhouette, connected by transparent inclined escalators and a light metal bridge on the 22nd floor. Such a "web" gives additional scale, contrasting with the arch's glass face.

The building of JSC "Samaraneftegaz" on Volzhsky Avenue in Samara (arch. bureau "ACD", arch. V.V. Lavrus, A.G. Golovin, 2003-2005) is a building-arch situated on the Volga embankment ("Fig. 2"). The project of the branch office is part of the whole conception of the redevelopment of the former "KINAP" plant's territory. This is a multi-functional business centre with a dwelling complex. According to the project, the 17-story office building belongs to the "CITY-terminal". Its urban significance is determined by its unique landscape role in the riverside. The building's compositional structure is determined by a number of factors and limitations: the radius of the business centre "fencing", the axis-perpendicular to the fairway of the Volga river, the red line of the embankment development, land use boundaries and traces of the demolished 7-story building. The office and dwelling blocks are separated by an arch - the main and only entrance to the CITY-terminal. The business centre features a branch office, a rental office centre, a bank, a hotel, cultural-exhibition and recreation complexes and multilevel parking. 

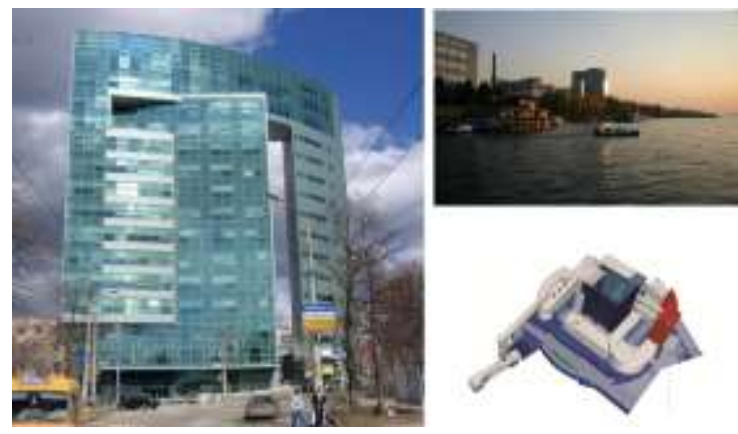

Fig. 2. The building of JSC "Samaraneftegaz" on Volzhsky Avenue in Samara (arch. bureau "ACD", arch. V.V. Lavrus, A.G. Golovin, 2003-2005)

In this example, we have focused on the topic of symmetrical (disymmetrical, asymmetrical) arch supports and their different functional content, respectively. We have also come to a serious issue of the viability of a building-arch when the function of one of the pillars has been lost, which will be manifested in the next analyzed object.

The Western City Gate in Belgrade, GENEX Tower (arch. Mihajlo Mitrovic, 1980) is a high-rise 35-story building of $\mathrm{h}=119 \mathrm{~m}$. It is located at the entrance to the city in New Belgrade. This is a volumetric composition consisting of a giant arch of two towers of different heights connected by a two-story bridge, with a rotating panoramic restaurant at the top. One of the towers is a business centre of the GENEX company, the other is higher and is used for living. The residential building has two entrances with semi-circular staircases. Currently, the office centre is almost completely empty, and the restaurant is closed. GENEX - previously a large-scale holding company with diversified activities - air transportation, tourism, foreign trade - has practically ceased to exist [7]. In this regard, the fate of the building, which is a two-support arch, an integral unbroken form and structure, is of great concern ("Fig. 3").

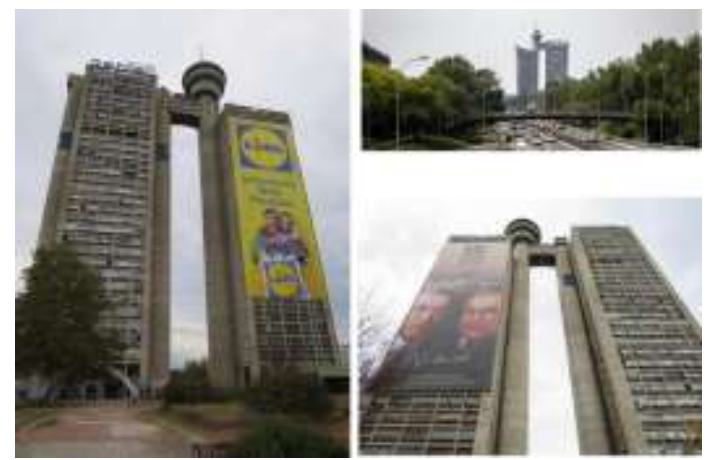

Fig. 3. GENEX Tower in Belgrade, arch. Mihajlo Mitrovic, 1980.

\section{FRAME, PORTAL}

A separate theme in the spatial potential of the building-arch is its role as an entrance portal, behind which something fundamentally different opens, like an action on a deep stage, separated from the auditorium by the portal frame. With a deep stage, the performance is initially perceived as a spectacle, the action develops in a different environment, in a "different world". The tradition that comes from the Renaissance and the Baroque, encourages us to consider the theme on the example of Italy.

The work of buildings-portals is based exactly on this principle. In that way "another Rome" Espositione Universale de Roma opens behind the Palace of civilizations Palazzo de Lavoro ( $\operatorname{arch} . \mathrm{M}$. Piacentini, 1938, arch. G. Guerrini, E. B. La Padula and M. Romano, 1950). A snow-white cube with dark rows of arches addressing the order language of the Coliseum, the main pavilion of the EUR ensemble has reflected the image of the state building of the 1930s in Italy - indisputable, absolute in its beauty, myth decor [8]. Behind the arches are galleries, behind the galleries there is a functionally filled volume. Nowadays the object is used for exhibitions and concerts.

The main building of the University of MilanoBicocca (arch. Vittorio Gregotti, 1996-1999) is a compositional centre of the campus built on the territory of the former industrial zone ("Fig. 4"). A linear deep-space composition develops in enfilades relative to the longitudinal axis. The laboratory buildings and student hostels are an enclave in a residential area in the North of the city with a separate students' life. The autonomy of the complex is emphasized by its bright terracotta-red colour scheme. Returning to the main building, it should be noted that the opening begins in it at fairly high levels - at the level of the 7th floor, it is crossed by a glass passage and is covered from above by three floors. This is a "window" into the public space, cut in a single volume. Note, that the centre of attraction outside the University, on the territory immediately adjacent to it, is the Teatro degli Arcimboldi (arch. V. Gregotti, 19972002) [9]. 

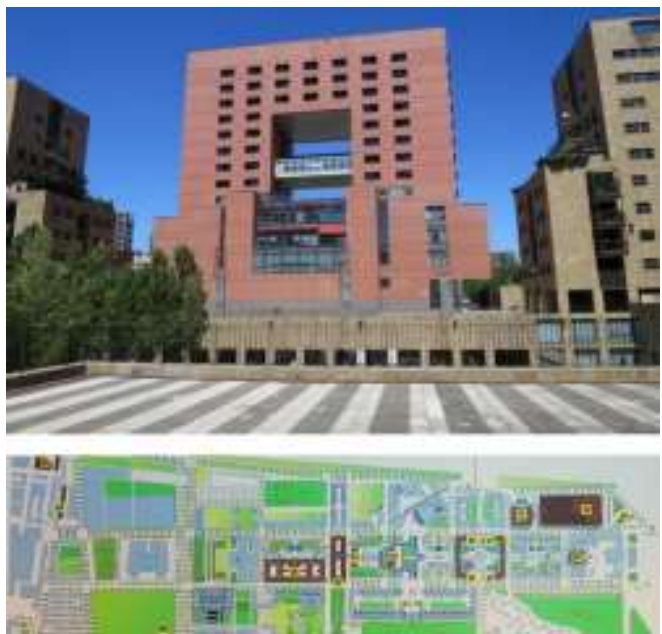

Fig. 4. The main building of the University of Milano-Bicocca, arch. Vittorio Gregotti, 1996-1999.

\section{Passage}

Passage is a covered gallery with two rows of shops and offices, which has exits to parallel streets [10] - in the context of this article, it is interesting for us as an expanded arch.

The covered market in Rotterdam (MVRDV, 2014) is a horseshoe-shaped building with glass-filled arched end facades. Having simple completed form, this building is functionally a hybrid that combines commercial and residential functions as the dominant ones. Inside the 40-meter arch there are 96 grocery stores and shops, 228 apartments of different configuration, 1200 parking spaces and an underground supermarket. The windows of each apartment face two sides: the kitchens are oriented to Markthal, the living rooms face the Meuse river [11]. To create a visual integrity with the surrounding space, the facade of the market is lined with Chinese granite which streets of Rotterdam are paved with.

The business Centre Cite Internationale in Lyon (arch. Renzo Piano, 2006) designating area between the Rhone and Saone rivers acts as an enclave in relation to the historical centre of the city. This is a two-line composition immersed in riverside greenery, ending with a semi-cylindrical volume of the amphitheatre at the confluence of the rivers. In plan, this is a giant horseshoe stretched along the inner street; the width of the inner street is almost equal to the width of the buildings framing it, which gives additional refinement to the spatial solution. Translucent coffered coverings are located on the inner street on the level of the 2nd3rd floors with recessions-slits from the enclosing walls; they seem to hover over the various functional areas of the open atrium. A large street toy in the form of people and animals is part of the dramatic composition of the general idea for the designation of functional zones. The sculptures are given such a size that they create an additional intermediate scale between the interior and exterior of the building, eliminating a clear border between them [12].

Representing a modern type of an architectural object, i.e. a building-space, the Cite Internationale interprets in a certain way the key theme of the historical environment of Lyon - through passages between streets and blocks - traboules. In the ideology of this article, it is a kind of arched spaces of courtyards.

\section{THE IDEOLOGY OF A TRIUMPHAL ARCH}

Of course, the building-arch produces the greatest impression when in its symbolism it goes back to the triumphal arch. The features of such buildings include the fact that, as a rule, they are symmetrical, which provides visual stability, excluding direct opposition of supports. In such objects, both methods of forming are used - subtraction and addition - organization of an opening in a single monolithic volume and connection of independent towers-supports with a third connecting volume, as well as decorative elements that work on a rich artistic image.

It is characteristic that the compositional technique of the "triumphal arch" is so strong that sometimes it is an arch with filling, without an opening in the direct physical sense, an imitation of an opening by reducing the visual mass of the central part of the volume ("Fig. 5"). It may be transparent filling (the Bank of America in Canary Wharf) or identification of the central part with a contrast material. So, the city hall in Portland, Oregon, (arch. Michael Graves, 1982) openly opposed to the architectural environment and urban landscape, emphasizes the management function as dominant.

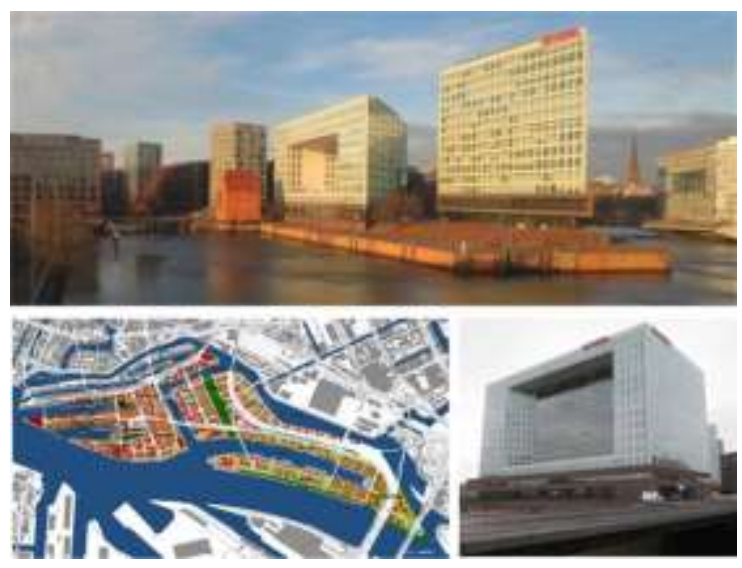

Fig. 5. HafenCity in Hamburg, "Spiegel"-building, arch. Bureau Hennig Larsen, 2011.

The Petronas twin towers, Kuala Lumpur, Malaysia, arch. Cesar Pelli, 1992-1998. The 88-storey towers more than $450 \mathrm{~m}$ high and with a total area of 395,000 
$\mathrm{m}^{2}$ accommodate offices, exhibition and conference halls, an art gallery, and a shopping centre. It is interesting, that the towers were built by two different companies to create competition and increase productivity. During the geological surveys, it turned out that one part of the proposed site for construction was on the edge of the rock, and the other - on soft limestone. Once built on that site, one of the towers would inevitably sink. As a result, both buildings were completely moved to the soft ground, shifted by $60 \mathrm{~m}$, and a pile foundation more than 100 meters deep was used. On the level of the 41st floor, the towers are connected by a covered walkway in the form of a twolevel pedestrian air bridge, Skybridge, on giant ball supports, which offers views of the city and surrounding area and provides fire safety of the building. Made in the form of ears of corn, the Petronas towers in plan represent an eight-pointed star - a symbol of integrity in Islam.

At the end of this section of the article, I will make a reservation that sometimes a triumphal arch is formed by volumes that are not connected to each other. The examples can be the towers of the German Bank in Frankfurt-am-Main, or the city hall in Oslo. However, the issue of the architectural form perception is the subject of another article.

\section{TRANSITION FROM BUILDINGS-ARCHES - TO COMPLEX SPATIAL STRUCTURES}

It is probably necessary to make a reservation that the typing proposed in this article is rather conditional, and the identified types sometimes pass one into another.

Thus, the use of several arches with openings and supports of a complicated shape is reflected in the volume composition of large objects.

The symbol of the Novosibirsk Akademgorodok is a kind of triumphal arch of 56-meter height, which may be interpreted as a slotted pyramid as well. These are two inclined 14-storey towers of the Technopark, connected on the level of the 13th floor by a walk gallery - a bridge over the road ("Fig. 6"). The bright colour scheme of the facade enhances the impression of an expressive form. Orange porcelain stoneware was used in the façade decoration. The "Media-façade" allows broadcasting graphic video and photo materials. The authors of the conception are the "SpaceConstruction" company, arch. D. Gerasimov, E. Savin, the general designer is JSC "Siberian Design Institute", V. Serova, A. Lotarev, V. Vilisov, 2012. According to the design, three towers were to be constructed, arranged at the vertexes of a conditional triangle; however, only two were built. The first of them houses the Information Technology Centre, the second one the Centre of Collective Use. Adjacent to the towers there are symmetrically located administrative buildings that house technological and service infrastructure (the Data Processing Centre, the Interdisciplinary Inter-University Master's Centre for Engineering Training, a hotel, a food court, a fitness centre). The first two floors are developed and protrude beyond the boundaries of the main volumes, giving the entire complex stability. A front staircase leads to the building, the space of which, together with the adjacent area, has been actively developed lately [13]
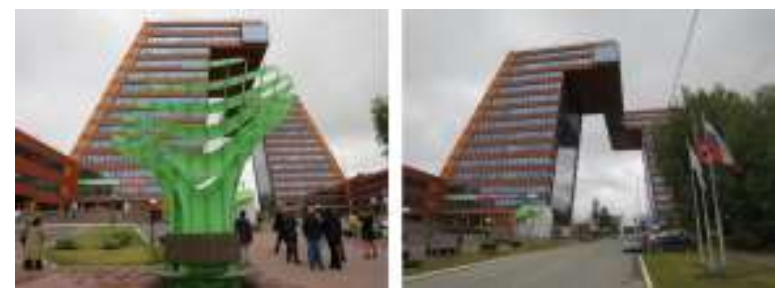

Fig. 6. Technopark in Novosibirsk Akademgorodok, arch. D Gerasimov, E.Savin, the general designer is JSC "Siberian Design Institute", V. Serova, A. Lotarev, V. Vilisov, 2012.

B. Raffaelli defined such shaping techniques as "open and closed folds" and urged to treat them with caution as distorting the perception of space [14].

In the shaping of buildings, pattern arches have become widespread, which can be interpreted as a transition from a laconic geometric form to a curved parametric architecture. From this position, the Paul Klee Centre in Bern, (arch. R. Piano, 2005) can be considered as a three-span arch with filling.

In the ideology of the modern approach to the consideration of the historical and architectural environment of cities, a fundamentally new type of arch is arched spaces of courtyards, which are widely used for connecting the external (a street) and the internal (a yard).

\section{CONCLUSION}

Having considered objects of various typologies, we are convinced that the architectural form of buildingsarches is quite universal, which allows to identify its typological potential, revealed in the following aspects:

Buildings-arches, fixing a transition state between the external and internal, public and private space, exist in two basic hypostases ("Fig. 6"):

- as an individual multifunctional building;

- as an element of public space — "gate, window, frame, portal" in the architectural environment.

Buildings-arches are used to accommodate a wide range of functions: business and shopping centres, banks, train stations, offices, housing, university complexes, and management buildings are located in them. 
For the organization of buildings-arches, two main methods of shaping are used - addition - connecting towers-supports with a bridge-transition, and subtraction - cutting out or marking an archway in the whole volume, as well as their combinations.

A giant arch as a symbol of power and victory in business, on one hand, and a symbol of invitation for co-operation, on the other hand, is a traditional form for business centres.

The shape of a building-arch inevitably makes it more complex and causes increase in the number of internal communications from the viewpoint of ensuring regulatory requirements. This dictates the appearance of bridges and walkways on the upper levels and uniting podiums on the lower ones.

There are widespread buildings-arches with filling, in which the opening is not a void, but is marked tectonically.

For buildings-arches, which are the dominant or accent of the deep-spatial composition, a bright colour solution is characteristic.

In the design of modern buildings-arches the following trends in the architectural form development have been identified, which may be characterized as transition from a laconic form to complex spatial structures:

- spatial multidirection and complexity of the outline of openings and supports;

- use of repeated arches instead of single ones;

- combination of circular and pattern outline.

\section{References}

[1] I.G. Lezhava, Function and structure of the form in architecture: Copy of the report on research works, Moscow: VNTITs, 1988, p. 38. [In Russian]

[2] Ibid.

[3] A.G. Rappaport, To the understanding of the architectural form I Doctoral thesis, Moscow, 2000. URL: https://archi.ru/lib/publication.html?id=1850569398 (accessed: 26.02.2020) [In Russian]

[4] A.V. Ikonnikov, Function, form, image in architecture, Moscow: Stroyizdat, 1986, p. 84. [In Russian]

[5] A.L. Gelfond, Architecture of public spaces, Moscow: INFRAM, 2019, pp. 118-122. (Scientific thought). [In Russian]

[6] A.V. Ikonnikov, Architecture of the XX century. Utopias and reality: in 2 vol. Vol. 2, Moscow: Progress-Traditsiya, 2003, pp. 466-467. [In Russian]

[7] “Western gate of Belgrade - GENEX tower". URL: https://lanasator.livejournal.com/234092.html (accessed: 26.02.2020). [In Russian]

[8] A.L. Gelfond, op. cit., pp. 155-157.

[9] C. Berizzi, Architectural Guide Milan. Buildings and Projects since 1919, Berlin: DOM publishers, 2015, pp. 198-201.
[10] "New dictionary of foreign words and expressions", Minsk. Kharvest, M.: JSC "Publishing house AST", 2001, p. 609. [In Russian]

[11] U. Yakovleva, Market Markthal. URL https://tatlin.ru/articles/Rynok_Markthal (accessed: 17.11.2016) [In Russian]

[12] A.L. Gelfond, op.cit., pp. 137-142.

[13] "Novosibirsk. Akademgorodok. Inclined towers of the Akadempark". URL: https://d popovskiy.livejournal.com/93099.html (accessed: 25.09.2015). [In Russian]

[14] R. Baires, The fast guide to architectural form, Amsterdam: BISPublishers Building Het Sieraad, 2016, p. 49. 